\title{
Cytogenetic and Immunohistochemical Characterization of Fragile X Syndrome in a Kuwaiti Family: Rapid Antibody Test for the Diagnosis of Mental Retardation Patients
}

\author{
Moussa Alkhalaf a Lilly Verghese ${ }^{a}$ Syed Khaja Mushtaq ${ }^{b}$ \\ a Department of Biochemistry, Faculty of Medicine, Kuwait University, and b Department of Pediatrics, \\ Al-Ahmadi Hospital, Kuwait
}

\section{Key Words}

Fragile X syndrome - Mental retardation - FMR1 protein . Kuwait

\begin{abstract}
Objectives: To study a Kuwaiti family with fragile $X$ mental retardation syndrome and present a rapid, noninvasive antibody test to be used for fragile $X$ syndrome diagnosis on all mentally retarded patients in Kuwait. Methods: For cytogenetic analysis, the fragile site was induced by culturing blood lymphocytes in a medium containing a low concentration of folate (M199) or by adding $0.1 \mu M$ of fluorodeoxyuridine to the culture media. For the immunohistochemical test on blood smears, monoclonal antibodies against fragile $X$ mental retardation (FMR1) gene product were used. The test is based on the presence of the protein in lymphocytes from normal individuals and its absence in lymphocytes from fragile $X$ patients. Results: A Kuwaiti family with fragile $X$ syndrome in 4 affected males is described. The immunohistochemical study with the monoclonal antibodies against FMR protein gave conclusive results on the same day for the affected males. Conclusion: To our knowledge, this is the first report describing a large Kuwaiti family with the fragile $X$ syndrome. These data suggest
\end{abstract}

that the immunohistochemical test used is an ideal method for the diagnosis of fragile $X$ syndrome in mentally retarded patients in Kuwait.

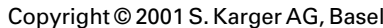

\section{Introduction}

Fragile $\mathrm{X}$ syndrome is the most common inherited form of mental retardation affecting 1 in 1,250 males and 1 in 2,000 females [1]. The disorder is cytogenetically characterized by the presence of an apparent breakage at the end of the long arm of the X chromosome (Xq27.3) when lymphocytes are cultured in a medium deficient in folic acid and thymidine [2]. Individuals with fragile $X$ syndrome present with both physical and nonphysical symptoms. Physical symptoms include large ears; a long, narrow face with a prominent forehead and a square chin, and increased testicular volume (macroorchidism) in males. Nonphysical symptoms include mental retardation (usually the most common symptom), developmental delay, learning disabilities, and autistic-like features. Females with the fragile $\mathrm{X}$ syndrome are less severely affected than males, having less mental retardation, fewer behavior problems, and less obvious physical symptoms [3].

\footnotetext{
Dr. Moussa Alkhalaf

Department of Biochemistry

Faculty of Medicine

PO Box 24923, 13110 Safat (Kuwait)

Tel. +965 5319489, Fax +965 5338908, E-Mail m_alkhalaf@hsc.kuniv.edu.kw
} 
With the cloning of the FMR1 gene responsible for the fragile $\mathrm{X}$ syndrome, the molecular basis of the disease and its unusual inheritance pattern have become much clearer $[4,5]$. The FMR 1 gene spans $38 \mathrm{~kb}$ and consists of 17 exons. In the noncoding $5^{\prime}$ end of the first exon of the gene is a trinucleotide repeat sequence, $\mathrm{CGG}$, which is present in normal individuals in a range of 6-50 copies. Expansion of the trinucleotide repeats sequence is associated with the disease. When the repeat lengths are expanded to 60-200 copies, the premutation, or carrier state, is seen in both males and females. The carrier state is not usually associated with a clinical phenotype. However, in carrier females there is a high probability for the premutation to expand upon transmission to yield a full mutation of 2301,000 copies of the CGG repeat and the fragile X syndrome [6].

Within the FMR 1 gene of affected individuals, the $\mathrm{C}$ residues present in the expanded CGG repeats and nearby $\mathrm{CG}$ repeats are hypermethylated. Hypermethylation interferes with the normal transcription of the FMR1 gene and results in the absence of both the FMR1 mRNA and protein. In a normal individual, the gene is unmethylated and produces normal amounts of protein, with the highest expression occurring in the brain and testes [7, 8]. All males with the full mutation show clinical symptoms. However, carrier males (known as transmitting males) can have premutations with CGG repeat numbers at the lower end of the premutation range and appear phenotypically normal since they still make adequate amounts of FMR1 protein [4].

In families with the fragile $\mathrm{X}$ syndrome, the disease gets worse in successive maternally derived generations, a phenomenon known as genetic anticipation. This characteristic is related to the expansion of the repeats from a premutation to a full mutation in carrier females and transmission of the full mutation to both sons and daughters [7].

Despite the high incidence of fragile $\mathrm{X}$ syndrome among mentally retarded patients on the worldwide level $[9,10]$, the disease is underdiagnosed among mentally retarded patients in Kuwait [11]. This may be due to the absence of an easy and reliable method which could be used to identify the disease in such patients. A Kuwaiti family with this disease is described and a rapid method for the diagnosis of this syndrome in mentally retarded males in Kuwait is presented.

\section{Materials and Methods}

\section{Cytogenetic Analysis}

The blood lymphocytes were cultured using whole blood in the presence of phytohemagglutinin to stimulate lymphocytic growth. To induce the fragile site, two different types of media were used: M199 medium containing low concentration of folate. The medium was supplemented with $4 \%$ of fetal bovine serum. The culture was incubated at $37^{\circ} \mathrm{C}, 5 \% \mathrm{CO}_{2}$ for 4 days; RPMI 1640 medium containing $10 \%$ fetal bovine serum for $96 \mathrm{~h} ; 0.1 \mu M$ of fluorodeoxyuridine (FUdR) was added to the medium $17 \mathrm{~h}$ before harvesting. Colcemid (final concentration: $0.25 \mu \mathrm{g} / \mathrm{ml}$ ) was added to the culture $1 \mathrm{~h}$ before harvesting. Cells were harvested and treated with hypotonic solution $(0.56 \%)$, then fixed with $3 \mathrm{v}$-methanol/1 $\mathrm{v}$-acetic acid. Slides were prepared according to standard protocols, then digested with trypsin $(0.05 \%)$ and stained with Giemsa $(5 \%)$. Karyotyping was done using IKAROS (Metasystems, Germany) and a Zeiss Axioplan microscope (Germany).

Immunohistochemical Test for Diagnosing Fragile X Syndrome

The method involved the use of monoclonal antibodies against the protein product of the FMR 1 gene. This rapid test is performed on blood smears and thus needs only one drop of blood [12]. Blood smears were made from one drop of blood. Slides were air-dried and fixed with $3 \%$ paraformaldehyde for $10 \mathrm{~min}$ at room temperature. Permeabilization of the cells was achieved by treating with $100 \%$ methanol for $20 \mathrm{~min}$. After washing with phosphate-buffered saline the slides were incubated with mouse monoclonal antibodies 1C3-1a (anti-fragile X mental retardation protein) obtained from Euromedex (France), then incubated with goat antimouse immunoglobulin conjugated with biotin (Jackson Immuno Research Laboratories, USA).

The biotin is visualized with streptavidin-biotinylated alkaline phosphatase complex (Zymed, UK). The new fuchsin substrate-chromogen system (DAKO, UK) is used for $2 \times 15 \mathrm{~min}$. The streptavidin-biotin-peroxidase complex was also used to visualize biotin (Zymed, UK). DAB solution was obtained from DAKO. Slides were counterstained with Gill's hematoxylin (Polysciences), mounted with aquamount solution (BDH) and examined with a Zeiss Axioplan microscope.

\section{Results}

\section{Pedigree of a Kuwaiti Family with Fragile X Syndrome}

The pedigree in figure 1 suggests that females II- 3 and II-4 are normal with no signs of mental retardation, but it is not known whether they are carriers or not. Male II-5 is normal with no signs of mental retardation. Males III-1 (age 26 years) and III-2 (age 30 years) have mental retardation and both of them are not married. They are expected to have the mutation. Males III-3, III-4, III-5 and females III-6, III-7 and III- 8 are normal with no signs of mental retardation. Parents III- 8 and III- 9 are first cousins having 3 children, 2 boys (IV-1 and IV-2), who are mentally retarded, and 1 girl (IV-3) with normal pheno- 


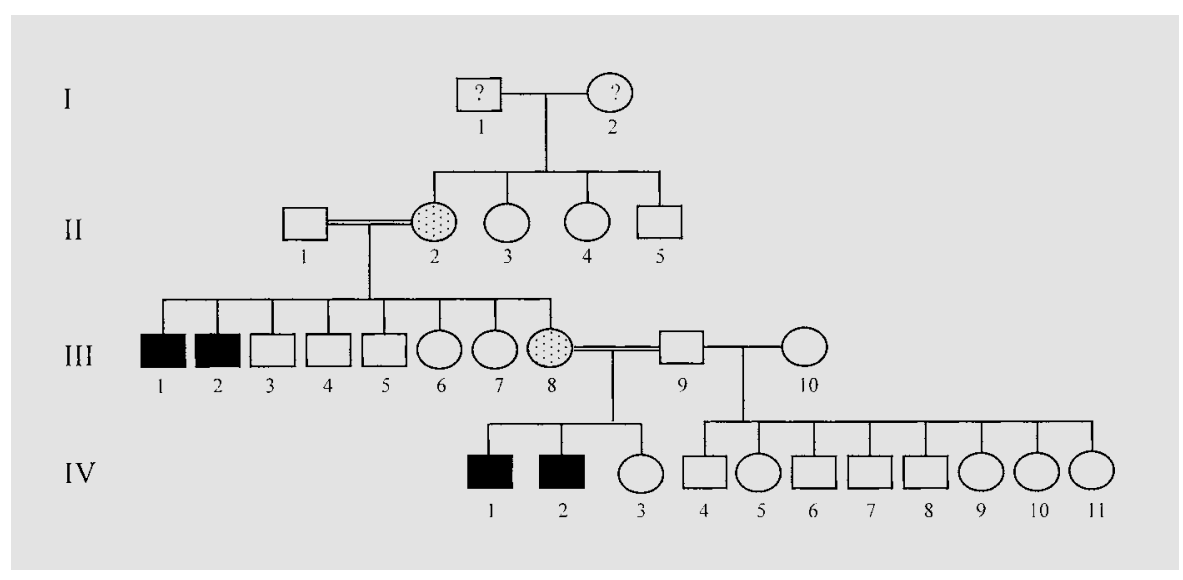

Fig. 1. Pedigree of a Kuwaiti family with fragile X syndrome. Males III-1, III-2, IV-1 and IV-2 are mentally retarded patients. Female II-2 is a carrier for the premutation.

Fig. 2. Fragile site at $X q 27.3$. a Normal $X$ chromosome from father III-9. b Normal $\mathrm{X}$ chromosome from carrier female III-8. c-d Several aspects of the fragile sites from male patient IV-1. e-g Fragile sites from male patient IV-2. Arrows show the breakage at the end of the long arm (Xq27.3).

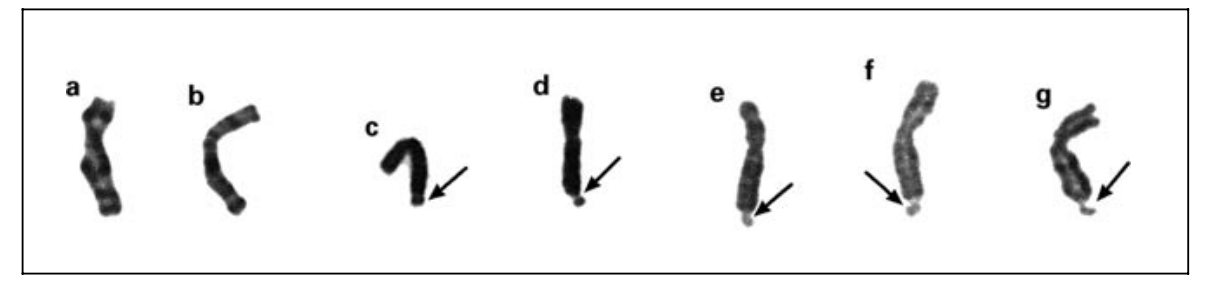

type. Male III-9 has 8 other children (IV-4 to IV-11) born from another wife (III-10), who is not related to him. All the 8 children (IV-4 to IV-11) are normal. This suggests that male III-9 is normal and that female III- 8 is a carrier for the mutation. The pedigree suggests female II- 2 to be a phenotypically normal female transmitting the defect to her cytogenetically normal daughter (III-8).

\section{Clinical Features of Affected Males (IV-I and IV-2)}

Male IV-2 was born in 1995 at full term; pregnancy and delivery were uneventful. The boy was sent to the Pediatric Clinic (Ahmadi Hospital) in October 1999 with a history of delayed and unclear speech. On examination he looked retarded with drooling of saliva and slurred speech. He responded to simple questions and obeyed simple orders. There was no hepatosplenomegaly. He showed subtle dysmorphic features, which included a triangular face, large prominent ears and a long philtrum. Neurological exam was normal. This patient showed some degree of behavioral features such as attention deficit hyperactivity disorder. The patient had recurrent upper respiratory tract infections, but there was no otitis media, which is a common medical problem in fragile $\mathrm{X}$ patients. The patient also showed a certain degree of strabismus. The rest of his examination was unremarkable.

Male IV-1 was born in 1989 at full term and was sent to the Pediatric Clinic in Ahmadi Hospital in November 1999. He showed the same clinical and medical features observed in patient IV-2.

\section{Abnormal Karyotype in Fragile X Patients}

Under the specialized culture conditions used in this experiment, cytogenetic analysis of the affected male IV-1 showed the fragile site at Xq27.3 (fig. 2c-d). The father of these 2 patients (III-9) did not show the fragile site (fig. 2a). This was expected since the father is normal as shown in figure 1 . The fragile site was not present in cells from the mother III-8 (fig. 2b), probably because she has a premutation with less than 200 CGG trinucleotide repeats in the $5^{\prime}$ UTR of the FMR 1 gene. The fragile site was also present in patient IV-2 (fig. 2e-g). The fragile site was induced in both M199 medium (folate-deficient medium) and RPMI 1640 supplemented with $0.1 \mu M$ FudR. The fragile site at Xq27.3 was present in $20 \%$ of the metaphases in these 2 patients.

\section{Analysis of FMR1 Protein in Fragile X Patients}

The immunocytochemical test used in this experiment is based on the presence of FMR 1 protein (FMRP) in normal lymphocytes and the absence of the protein in lymphocytes of fragile $\mathrm{X}$ patients. FMRP was visualized in blood smears by a three-step immunoincubation procedure using both the streptavidin-biotin-alkaline phosphatase and streptavidin-biotin-peroxidase complexes. In every blood smear, at least 50 lymphocytes were examined and scored for the presence of FMRP. Six blood samples from 6 individuals were analyzed, 2 controls (normal individuals without any sign of mental retardation or any other clinical symptoms related to fragile $\mathrm{X}$ syndrome), 2 male patients (IV-1 and IV-2), both of them with mental 


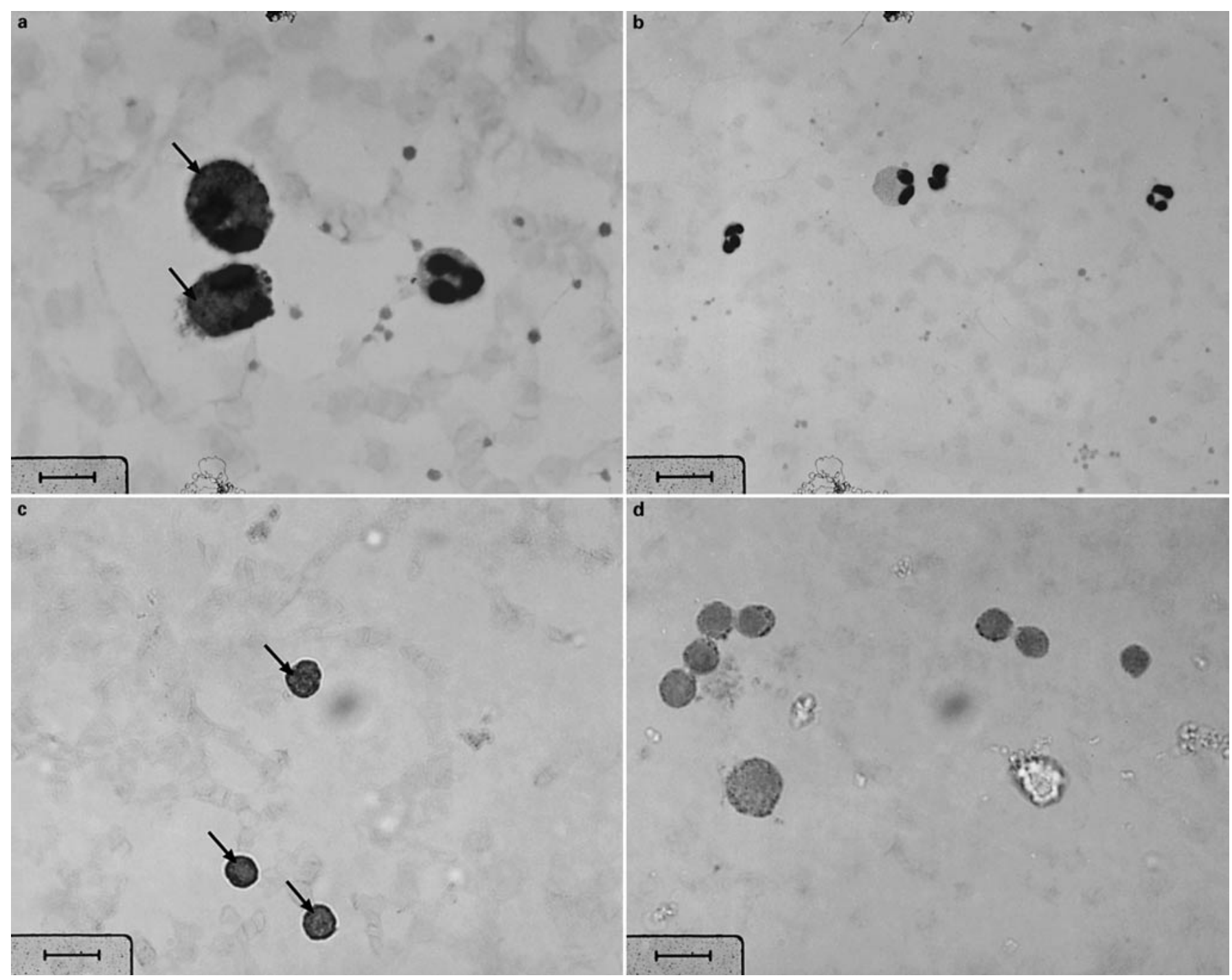

Fig. 3. Analysis of FMRP on blood smears of patients. The protein was visualized with streptavidin-biotin-alkaline phosphatase procedure $(\mathbf{a}, \mathbf{b})$ and with streptavidinbiotin-peroxidase complex $(\mathbf{c}, \mathbf{d})$. In a and $\mathbf{c}$ blood smears obtained from normal individuals and in $\mathbf{b}$ and $\mathbf{d}$ blood smears are from fragile $\mathrm{X}$ patients. In both procedures, the protein is present in the cytoplasm of lymphocytes of normal individuals (arrows) and is absent in fragile $\mathrm{X}$ patients. Slides were counterstained with Gill's hematoxylin. Bar: $10 \mu \mathrm{m}$.

retardation and whose cytogenetic test showed the fragile $\mathrm{X}$ chromosome. The blood of the father (III-9) and mother (III-8) was also analyzed (in both cases, clinical symptoms of fragile $\mathrm{X}$ syndrome were absent and the cytogenetic test showed normal karyotypes). In blood smears from control individuals, FMRP is detected in the cytoplasm of lymphocytes (fig. 3a, c), whereas the lymphocytes of both fragile X patients were devoid of FMRP (fig. 3b, d) because of the lack of transcription caused by the hypermethylation of the promoter region of the FMR1 gene [7]. The FMRP was also detected in the lymphocytes of the mother and father (data not shown). Both of them do not have mental retardation and karyotypes were normal. FMRP was detected with streptavidin-biotin-alkaline phosphatase complex (fig. 3a, b) and with streptavidin-biotin-peroxidase complex (fig. 3c, d). 


\section{Discussion and Conclusion}

Before the cloning of the fragile $\mathrm{X}$ gene, the diagnosis of the disease was based on the detection of the fragile site at Xq27.3 by cytogenetic analysis, which is a delicate, tedious, and not completely reliable method. The cytogenetic test is least reliable in the detection of clinically normal male and female carriers [13]. Despite the high incidence of the disease [9, 10], little is known about the frequency of the syndrome in Kuwait, though it is considered to be the second most prevalent mental retardation disorder after Down's syndrome on the worldwide level. In Kuwait, a disease profile of 400 institutionalized mentally retarded patients showed only 5 cases with fragile $\mathrm{X}$ syndrome [11]. Identification of the fragile site was done on 9 patients with macrotestes by using cytogenetic analysis on peripheral blood cultured in MEM-FA medium culture; 5 of them showed the fragile site. From the study by Farag et al. [11] it was not clear whether they analyzed all the 400 mentally retarded patients for the fragile $\mathrm{X}$ or restricted their analysis to the 9 patients with macrotestes. In addition, the same study shows that the frequency of Down's syndrome among the mentally retarded patients in Kuwait is $8.5 \%$. Other studies on the frequencies of fragile $\mathrm{X}$ syndrome among mental retardation patients show much higher frequencies. In Italy, Perroni et al. [9] studied 453 mentally retarded patients and showed that fragile X syndrome is present in $22 \%$. In another study in Croatia, Hecimovic et al. [10] studied 108 patients with mental retardation and showed that 14 (13\%) of them were affected with fragile $\mathrm{X}$ syndrome. These data suggest to us that this syndrome is underdiagnosed in Kuwait and that a further effort must be made to detect unrecognized cases during the screening of mentally retarded patients.
The cloning of the fragile $\mathrm{X}$ mental retardation gene [5-7] has given rise to new prospects for identifying fragile $\mathrm{X}$ patients with direct diagnosis by using PCR analysis and DNA probe in Southern blotting $[14,15]$. The DNAbased method is the most reliable method for the detection of full mutation, but it generally takes more than 1 week and needs an established laboratory in molecular biology.

After the production of monoclonal antibodies for FMR1 protein product $[16,17]$, it was shown that in normal individuals, the FMR1 gene is expressed in almost every tissue and cell type. In affected patients, lack of expression of FMRP in most tissues and cell types is responsible for the mental retardation. Thus, the absence or presence of FMRP in cells was used as a diagnostic tool. This antibody test was used for the detection of the FMRP on blood smears of mentally retarded patients. This rapid, noninvasive test gave conclusive results on the same day of the experiment. The cytogenetic method confirmed the results obtained with the monoclonal antibodies test. We suggest using this immunohistochemical test in the diagnosis of all mentally retarded patients in Kuwait, as the use of this method will improve the diagnosis of fragile $\mathrm{X}$ syndrome in mentally retarded patients. Identifying patients with this syndrome could lead to improved understanding of the cause of their problems and availability of adequate support for their behavioral and physical problems with an option for prenatal diagnosis.

\section{Acknowledgment}

We thank Maya Bakir for technical support and Prof. Saghir Akhtar for critical reading of the manuscript. This work was supported by grant MB 028 from Kuwait University.

\section{References}

1 Warren ST, Nelson DL: Advances in molecular analysis of fragile X syndrome. JAMA 1994; 271:536-542.

2 Bailey DB, Nelson D: The nature and consequences of fragile X syndrome. Men Retard Dev Disabilities Res Rev 1995;1:238-244.

3 Sutherland GR: Heritable fragile sites on human chromosome. I. Factors affecting expression in lymphocyte culture. Am J Hum Genet 1979;31:125-135.

4 De Vries BBA, Halley DJJ, Oostra BA, Niermeijer MF: The fragile X syndrome. J Med Genet 1998;35:579-589.

Cytogenetic and Immunohistochemical

Characterization of Fragile X Syndrome
5 Rousseau F, Heitz D, Biancalana V, Blumenfield S, Kretz C, Boue J, Tomerup N, van der Hagen $\mathrm{C}$, deLozier-Blanchet $\mathrm{C}$, Crouquette MF, Gilgenkrantz S, Jalbert P, Voelckel MA, Oberle I, Mandel JL: Direct diagnosis by DNA analysis of the fragile $\mathrm{X}$ syndrome of mental retardation. N Engl J Med 1991;325:16731681.

6 Verkerk AJMH, Pieretti M, Sutcliff JS, Fu Y, Kuhl DPA, Pizzuti A, Reiner O, Richards S, Victoria MF, Zhanh F, Eussen BE, van Ommen GB, Blonden LAJ, Riggins GJ, Chastain JL, Kunst CB, Galjaard H, Cakey CT, Nelson DL, Oostra BA, Warren ST: Identification of a gene (FMR-1) containing a CGG repeat coinci- dent with a breakpoint cluster region exhibiting length variation in fragile $\mathrm{X}$ syndrome. Cell 1991;65:905-914

7 Oberle I, Rousseau F, Heitz D, Kretz C, Devys D, Hanauer A, Boue J, Bertheas MF, Mandel JL: Instability of a 550-base pair DNA segment and abnormal methylation in fragile $\mathrm{X}$ syndrome. Science 1991;252:1097-1102.

8 Mandel JL, Heitz D: Molecular genetics of the fragile X syndrome: A novel type of unstable mutation. Curr Opin Genet Dev 1992;2:422 430. 
9 Perroni L, Grasso M, Argusti A, Lo Nigro C, Croci GF, Zelante L, Garani GP, Dagna Bricarelli F: Molecular and cytogenetic analysis of the fragile $\mathrm{X}$ syndrome in a series of 453 mentally retarded subjects: A study of 87 families. Am J Med Genet 1996;64:176-180.

10 Hecimovic S, Barisic I, Pavelic K: DNA analysis of the fragile $\mathrm{X}$ syndrome in an at risk pediatric population in Croatia: Simple clinical preselection criteria can considerably improve the cost-effectiveness of fragile $\mathrm{X}$ screening studies. Hum Hered 1998;48:256-265.

11 Farag TI, al-Awadi SA, el-Badramary MH, Aref MA, Kasrawi B, Krishna Murthy DS, elKhalifa MY, Yadav G, Marafie MJ, Bastaki L, et al: Disease profile of 400 institutionalized mentally retarded patients in Kuwait. Clin Genet 1993;6:329-334.
12 de Vries BB, Mohkamsing S, van den Ouweland AM, Halley DJ, Niermeijer MF, Oostra BA, Willemsen R: Screening with the FMR1 protein test among mentally retarded males. Hum Genet 1998;103:520-522.

13 Jacky PB, Ahuja YR, Anyane-Yeboa K, Breg WR, Carpenter NJ, Froster-Iskenius UG, Fryns JP, Glover TW, Gustavson KH, Hoegerman SF, et al: Guidelines for the preparation and analysis of the fragile $\mathrm{X}$ chromosome in lymphocytes. Am J Med Genet 1991;48:460467.

14 Sutherland GR, Gedeon A, Kornman L, Donnelly A, Byard RW, Mulley JC, Kremer E, Lynch M, Pritchard M, Yu S, Richards RI: Prenatal diagnosis of fragile $\mathrm{X}$ syndrome by direct detection of the unstable DNA sequence. N Engl J Med 1991;325:1720-1722.
15 Yamauchi M, Nagata S, Seki N, Toyama Y, Harada N, Niikawa N, Masuno I, Kajii T, Hori $\mathrm{T}$ : Prenatal diagnosis of fragile $\mathrm{X}$ syndrome by direct detection of the dynamic mutation due to an unstable DNA sequence. Clin Genet 1993;44:169-172.

16 Devys D, Lutz Y, Rouyer N, Bellocq JP, Mandel JL: The FMR-1 protein is cytoplasmic, most abundant in neurons and appears normal in carriers of a fragile $\mathrm{X}$ premutation. Nat Genet 1993;4:335-340.

17 Willemsen R, Mohkamsing S, de Vries B, Devys $D$, van den Ouwelan A, Mandel JL, Galjaard H, Oostra B: Rapid antibody test for fragile S syndrome. Lancet 1995;345:1147-1148. 